\title{
Life course body mass index and risk of knee osteoarthritis at the age of 53 years: evidence from the 1946 British birth cohort study
}

\author{
Andrew K Wills, ${ }^{1}$ Stephanie Black, ${ }^{1}$ Rachel Cooper, ${ }^{1}$ Russell J Coppack, ${ }^{2}$ \\ Rebecca Hardy, ${ }^{1}$ Kathryn Remmes Martin, ${ }^{1}$ Cyrus Cooper, ${ }^{3}$ Diana Kuh ${ }^{1}$
}

\begin{abstract}
- Additional data
(supplementary tables and figures) are published online only at http://ard.bmj.com/ content/71/5.toc)
\end{abstract}

${ }^{1}$ MRC Unit for Lifelong Health and Ageing, University College London, London, UK

${ }^{2}$ DMRC Headley Court, Epsom, UK

${ }^{3}$ MRC Lifecourse Epidemiology Unit, University of Southampton, Southampton, UK

\section{Correspondence to}

Dr Andrew K Wills, MRC Unit for Lifelong Health and Ageing, University College London, 33 Bedford Place, London WC1B

5JU, UK;

a.wills@nshd.mrc.ac.uk

Accepted 14 August 2011

Published Online First

6 October 2011

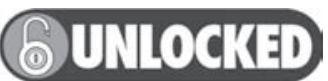

This paper is freely available online under the BMJ Journals unlocked scheme, see http:// ard.bmj.com/info/unlocked.dtl

\begin{abstract}
Introduction The authors examined how body mass index (BMI) across life is linked to the risk of midlife knee osteoarthritis $(\mathrm{OA})$, testing whether prolonged exposure to high $\mathrm{BMI}$ or high $\mathrm{BMl}$ at a particular period has the greatest influence on the risk of knee OA.
\end{abstract}

Methods A population-based British birth cohort of 3035 men and women underwent clinical examination for knee $\mathrm{OA}$ at age 53 years. Heights and weights were measured 10 times from 2 to 53 years. Analyses were stratified by gender and adjusted for occupation and activity levels.

Results The prevalence of knee OA was higher in women than in men $(12.9 \%(n=194)$ vs $7.4 \%(n=108))$. In men, the association between $\mathrm{BMl}$ and later knee $\mathrm{OA}$ was evident at 20 years $(p=0.038)$ and remained until 53 years (OR per z-score $1.38(95 \% \mathrm{Cl} 1.11$ to 1.71$))$. In women, there was evidence for an association at 15 years $(p=0.003)$; at 53 years, the OR was 1.89 (95\% Cl 1.59 to 2.24) per z-score increase in BMl. Changes in BMl from childhood in women and from adolescence in men were also positively associated with knee OA. A structured modelling approach to disentange the way in which BMI is linked to knee $\mathrm{OA}$ suggested that prolonged exposure to high BMl throughout adulthood carried the highest risk and that there was no additional risk conferred from adolescence once adult BMI had been accounted for. Conclusion This study suggests that the risk of knee OA accumulates from exposure to a high BMl through adulthood.

\section{INTRODUCTION}

Regardless of study design (eg, cross-sectional, casecontrol or prospective cohort) or case definition, body mass index (BMI) is strongly and positively associated with knee osteoarthritis (OA) across its distribution, ${ }^{1}$ and there is some evidence of a relationship with disease progression. ${ }^{2-5}$ However, few studies have reported on its association with BMI at different ages $^{6-11}$; among those studies that have, most have relied on recall of body size,,-12 and none has examined BMI across life from childhood to mid-adulthood. Thus, while the association between overweight and $\mathrm{OA}$ is considered causal through mechanical or metabolic pathways, ${ }^{13}$ the way in which lifetime BMI is linked with future OA remains unclear. For example, does cumulative exposure to high BMI over a prolonged period of time drive OA risk, or is there a period in life when carrying excess weight is particularly detrimental? This information is important for informing best practices on the prevention of $\mathrm{OA}$ and may provide an insight into pathways across life by which BMI is linked to OA.13

We use a general population-based British birth cohort study to examine the relationship between lifetime BMI and knee OA at 53 years. Our aims were to: (1) determine how early in life BMI is associated with knee OA; (2) examine the influence of changes in BMI during specific periods of life; (3) assess whether prolonged exposure to high BMI throughout life increases the risk of knee OA or whether being exposed to a high BMI at a particular stage of life is the most important way in which weight affects risk $^{14}$; and (4) assess whether these relationships differ by gender since some studies have reported stronger associations in women. ${ }^{691215-18}$

\section{METHODS}

\section{Study sample}

The Medical Research Council National Survey of Health and Development is a socially stratified birth cohort of 2547 women and 2815 men who have been followed up since their birth in 1946. This paper uses information on knee OA that was collected when cohort members were 53 years of age and includes 3035 participants (1472 men and 1563 women). The majority $(\mathrm{n}=2989)$ were examined in their own homes by trained research nurses. Those who were successfully contacted were, in most respects, representative of the UK-born population of that age. ${ }^{19}$ Contact was not attempted for 1979 individuals who either had previously refused to take part, were living abroad, remained untraced since last contact at 43 years or had already died. Data collection received ethical approval from the Medical Research Council ethics committee, and informed consent was given by respondents at each wave.

\section{Outcome}

We used the American College of Rheumatology criteria for the clinical diagnosis of idiopathic knee $\mathrm{OA},{ }^{20}$ namely knee pain in either knee on most days for at least 1 month in the last year and at least two of the following: stiffness, crepitus, bony tenderness and bony enlargement. These items were assessed through a clinical examination conducted by a trained research nurse (see online supplementary text $\mathrm{S} 1$ for full details of the examination). As an indicator of functional limitations in those with knee OA, we also report the average time taken 
to complete 10 chair rises, which was performed using a standardised protocol. ${ }^{21}$

\section{Exposure}

Heights and weights were measured with standardised protocols at ages $2,4,7,11,15,36,43$ and 53 years, and were selfreported prospectively at ages 20 and 26 years. We calculated BMI (weight $(\mathrm{kg}) /$ height $\left(\mathrm{m}^{2}\right)$ ) at each age and converted these into z-scores, normalising and standardising by age and sex using the LMS method. ${ }^{22}$

\section{Covariables}

The Registrar General's classification of own occupation in adulthood at 43 years, categorised into manual and non-manual occupations, was used. To avoid reverse causation where symptoms of knee OA can cause individuals to modify their activity level, we used the level of participation in sports and recreational activities collected at age 36 years. This variable assessed the frequency and duration of participation in 27 activities (including badminton, swimming, football and jogging over the last month) split into three categories: inactive=no reported activity; less active $=$ one to four times; more active=five or more times.

\section{Analysis}

Analyses were stratified by gender, with interactions assessed using Wald tests. We first plotted the mean lifetime BMI (z-score) in individuals with knee $O A$ and estimated unadjusted and adjusted (controlling for activity and adult occupation) ORs for the association between BMI at each age and knee OA using logistic regression (aim 1). BMI was modelled using both standardised z-scores and raw units $\left(\mathrm{kg} / \mathrm{m}^{2}\right)$. Z-scores allowed for a comparison of effect sizes across ages, uninfluenced by the widening distribution of BMI with age. Raw units were examined to allow for a comparison with other studies and to more directly capture the mechanical overload hypothesis. ${ }^{23}$ There was no evidence for a departure from linearity, as tested using quadratic terms and by inspecting plots of observed versus predicted values.

We examined the influence of changes in BMI during five specific life periods (childhood: $2-7$ years; childhood to adolescence: 7-15 years; adolescence to young adulthood: $15-20$ years; early adulthood: 20-36 years; mid-adulthood: 36-53 years) (aim 2) by adjusting for BMI at the start of each interval. The associations are therefore conditional on size at the start of the interval, removing any of the association due to BMI tracking. This conditional variable can be interpreted as BMI change above or below that expected in our population given earlier BMI.

We used a structured modelling approach ${ }^{24}$ to provide an insight into the way in which high BMI over life is associated with knee OA (aim 3). Each individual's lifetime BMI trajectory was simplified according to whether or not they were in the top quartile of the sex-specific BMI distribution (high BMI) at age 15,26 and 43 years, giving eight possible trajectories. These ages approximate adolescence, early adulthood and mid-adulthood, although similar results were found in a sensitivity analysis using other ages. The top quartile, rather than overweight cutoff $\left(>25 \mathrm{~kg} / \mathrm{m}^{2}\right)$, was used to avoid zero cell counts in trajectory groups. The results were similar in a sensitivity analysis using the upper tertile (see online supplementary table S1). A saturated model was first fitted by allowing each possible trajectory to explain knee OA. Sets of model constraints were then imposed, with each corresponding to a type of life course risk model. ${ }^{14}$ In each case, the model with the constraints was tested against the saturated model using the $\chi^{2}$ distribution, and the $p$ value was used as an indicator of model fit. Higher $p$ values reflect a better model fit since they indicate that the more parsimonious (constrained) model fits the data as well as the more complex (saturated) model. The life course models considered were as follows: (1) an accumulation model where only the duration of high BMI is allowed to explain knee OA (duration);
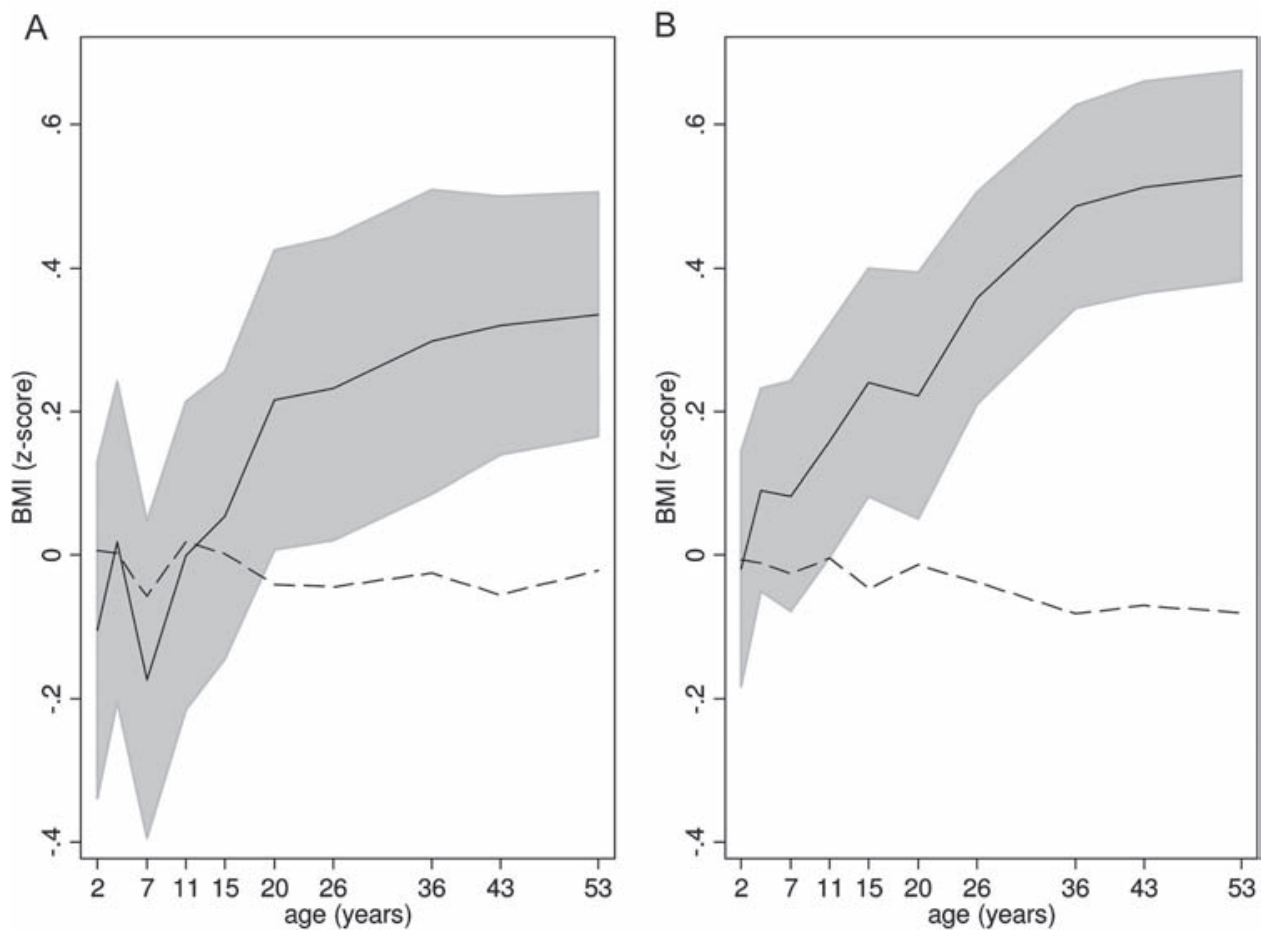

Figure 1 Mean lifetime body mass index (BMI) z-score and 95\% $\mathrm{Cl}$ (shaded area) in men (A) and women (B) among those with knee osteoarthritis $(\mathrm{OA}$; solid line) at age 53 years. The dashed line is the mean BMI pattern in individuals without knee $0 \mathrm{~A}$ at age 53 years. 
A

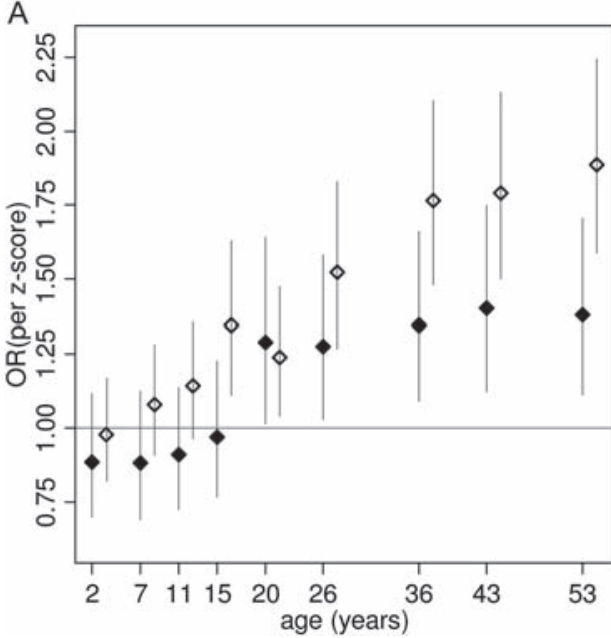

B

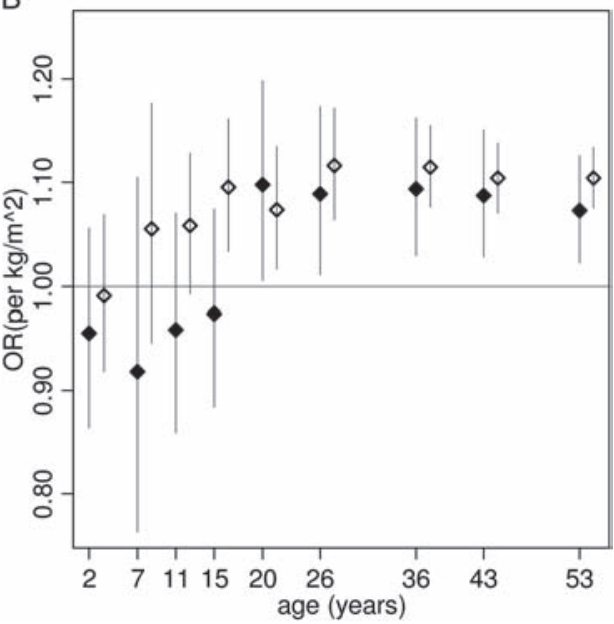

Figure 2 Odds ratios (OR) for knee osteoarthritis in men (filled markers) and women (open markers) per z-score increase in body mass index (BMI) at each age $(A)$ and per $\mathrm{kg} / \mathrm{m}^{2}$ increase in BMI (B). Adjusted for activity levels and occupation (manual/non-manual). Evidence for a sex interaction using BMI z-scores at ages 15 years $(p=0.035)$ and 53 years $(p=0.025)$ and weak evidence at ages 36 years $(p=0.051)$ and 43 years $(p=0.089)$. Evidence for sex interaction using nonstandardised BMI at age 15 years $(p=0.043)$.

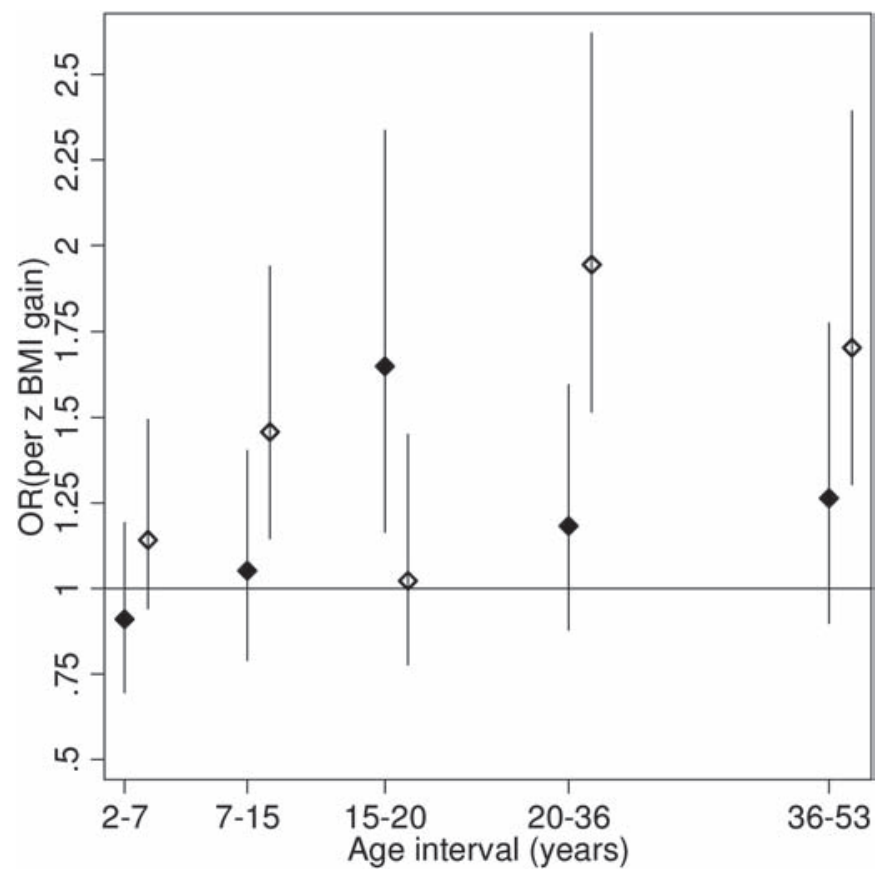

Figure 3 Association (OR) between conditional body mass index (BMI) change (per z-score increase) and knee osteoarthritis in infancy (2-7 years), childhood/adolescence (7-15 years), adolescence to young adulthood (15-20 years), early adulthood (20-36 years) and mid-adulthood ( $36-53$ years) in men (filled markers) and women (open markers). Each period of BMI change is adjusted for BMI at the beginning of the interval. Adjusted for activity levels and occupation (manual/non-manual). Sex interactions: $7-15$ years: $p=0.088 ; 15-20$ years: $p=0.035 ; 20-36$ years: $p=0.012$.

(2) an accumulation model that is similar to (1) but additionally allows the effect of high BMI to vary by age of exposure (duration and age); and (3) period models where each period is separately allowed to explain knee OA risk. Online supplementary text S2 gives the algebraic formulation of each model.

To examine the influence of potential secondary OA on our findings, we repeated the analyses after excluding cases who had reported ever seeing a doctor about a knee injury on the limb diagnosed as having $\mathrm{OA}$. We extended this by additionally excluding those with unilateral OA. Stata (V.10.1) was used for all analyses.

\section{RESULTS}

At age 53 years, $302(10.2 \%)$ individuals were classified with knee OA. The prevalence was higher in women than in men: $12.9 \%(n=194)$ versus $7.4 \%(n=108)(O R$ in women $1.84(95 \%$ CI 1.44 to 2.36)); adjusting for BMI at age 53 years slightly attenuated this association (OR 1.76). Thirty-eight per cent of individuals with knee OA had bilateral symptoms, with little evidence of a gender difference in this proportion $(p=0.1)$. Of individuals with knee OA, $16.2 \%$ were unable to take or complete the 10 chair rise test, compared to $4.1 \%$ of other participants $(p<0.001)$. Those with knee OA who were able to complete 10 chair rises took, on average, $14 \%$ longer ( $95 \%$ CI $8.9 \%$ to $19.4 \%$ ) than individuals without knee OA.

From age 36 years, women had faster BMI gains, and their BMI distribution was more positively skewed compared to men (see online supplementary figure S1). More men than women were in manual occupations (39\% vs $29 \%$, p<0.001). Women were less likely to participate in sports and recreational activities at age 36 years compared to men ( $\%$ inactive: $41 \%$ vs $31 \%$, $p<0.001$ ).

\section{Life course $\mathrm{BMI}$ and knee $\mathrm{OA}$}

The BMI pattern among women who developed knee OA deviated from the rest of the population from 2 years such that, by age 53 years, they had a mean BMI that is 0.61 SD higher than that of women without knee OA (figure 1). The pattern was similar in men, but the accrual of extra weight began later (around 11-15 years), and the difference in BMI at 53 years between those with knee $\mathrm{OA}$ and those without knee OA was smaller (0.36 SD).

Figure 2A shows the association between BMI z-scores at each age and knee OA. Adjusting for occupation and activity only slightly attenuated the crude estimates (crude not shown). In men, the association was evident at 20 years $(p=0.038)$ and remained until 53 years; there was no evidence for an association with BMI in childhood. In women, there was weak evidence for a positive association as early as 11 years (OR per SD increase in BMI 1.16 (95\% CI 0.98 to 1.38)); at 53 years, the odds of knee OA was $94 \%$ higher for each z-score increase in BMI. 
Table 1 Adult life course models testing the way in which exposure to high BMI (top quartile) in adulthood might affect later life knee $0 \mathrm{~A}$

\begin{tabular}{|c|c|c|c|c|c|c|c|c|c|c|}
\hline & \multirow{2}{*}{\multicolumn{2}{|c|}{$\begin{array}{l}\text { BMI trajectory } \\
1=\text { high }\end{array}$}} & \multirow{2}{*}{\multicolumn{2}{|c|}{$\begin{array}{l}\text { BMI }\left(\mathbf{k g} / \mathbf{m}^{2}\right) \\
\text { Median }\end{array}$}} & \multirow[b]{3}{*}{$\mathbf{N}(\%)$} & \multirow[b]{3}{*}{ Knee OA (\%) } & \multicolumn{4}{|c|}{ Life course models (test of fit against the saturated model ${ }^{*}$ ) } \\
\hline & & & & & & & \multirow{2}{*}{$\begin{array}{l}\text { Accumulation } \\
\text { (duration) }^{\dagger}\end{array}$} & \multirow{2}{*}{$\begin{array}{l}\text { Accumulation } \\
\text { (duration and age) }\end{array}$} & \multirow{2}{*}{$\begin{array}{l}\text { Period }^{\S} \text { (early } \\
\text { adulthood) }\end{array}$} & \multirow{2}{*}{$\begin{array}{l}\text { Period } \\
\text { (mid-adulthood) }\end{array}$} \\
\hline & 26 Years & 43 Years & 26 Years & 43 Years & & & & & & \\
\hline \multirow{3}{*}{ Men } & 1 & 0 & 26.0 & 26.0 & $114(9.1)$ & 8.8 & \multirow{3}{*}{$\begin{array}{l}\chi^{2}(2)=1.65 \\
p=0.438\end{array}$} & \multirow{3}{*}{$\begin{array}{l}\chi^{2}(1)=1.19 \\
p=0.276\end{array}$} & \multirow{3}{*}{$\begin{array}{l}\chi^{2}(2)=3.79 \\
p=0.150\end{array}$} & \multirow{3}{*}{$\chi^{2}(2)=1.37 ; p=0.504$} \\
\hline & 0 & 1 & 23.7 & 28.8 & $118(9.4)$ & 11.0 & & & & \\
\hline & 1 & 1 & 27.1 & 30.5 & 194 (15.5) & 9.3 & & & & \\
\hline \multirow[t]{2}{*}{ Women } & 0 & 0 & 21.0 & 22.9 & $870(65.6)$ & 8.5 & \multirow{2}{*}{$\begin{array}{l}\chi^{2}(2)=3.31 \\
\mathrm{p}=0.191\end{array}$} & \multirow{2}{*}{$\begin{array}{l}\chi^{2}(1)=0.55 ; \\
\mathbf{p}=0.458\end{array}$} & \multirow{2}{*}{$\begin{array}{l}\chi^{2}(2)=26.16 ; \\
p<0.001\end{array}$} & \multirow{2}{*}{$\begin{array}{l}\chi^{2}(2)=5.09 ; \\
p=0.078\end{array}$} \\
\hline & 1 & 1 & 26.2 & 31.1 & $206(15.5)$ & 26.7 & & & & \\
\hline
\end{tabular}

\footnotetext{
${ }^{*}$ The saturated model allows each BMI trajectory to affect the likelihood of knee $0 \mathrm{~A}$. The model that differs the least from the saturated model in terms of explaining knee $0 \mathrm{~A}$ is the one with most support. Hence, larger $\mathrm{p}$ values indicate a better model (highlighted in boldface).

${ }^{\dagger}$ Accumulation (duration): this model assumes that the effect of having a high BMI is the same at each age, that is, it is only the amount of time exposed that is important (see online supplementary text $\mathrm{S} 2)$.

${ }^{\ddagger}$ Accumulation (duration and age): this model is the same as the duration model but also allows the effect of having a high BMI to differ at each age, that is, exposure time and age of exposure are allowed to influence the likelihood of knee OA (see online supplementary text S2).

§Period: These models allow exposure to affect knee $O A$ at one age only.

$\mathrm{BMI}$, body mass index; OA, osteoarthritis.
}

On the normalised and standardised scale, the association between BMI and knee OA was 39\% ( $p=0.035), 31 \%(p=0.051)$, $28 \%(p=0.089)$ and $37 \%(p=0.025)$ stronger in women than in men at ages 15, 36, 43 and 53 years, respectively (figure 2A). However, with the exception of the gender interaction at 15 years $(p=0.043)$, these gender differences were almost entirely removed when raw BMI units $\left(\mathrm{kg} / \mathrm{m}^{2}\right)$ were used(figure $\left.2 \mathrm{~B}\right)$.

These results were qualitatively similar after removing cases of suspected secondary knee OA due to a knee injury (see online supplementary text S4.1). The associations between BMI and knee OA were larger but had a similar pattern across age and gender after further exclusion of unilateral knee OA (see online supplementary text S4.1).

\section{Conditional BMI change}

In men, conditional BMI gain from 15 to 20 years was associated with a higher risk of knee OA (figure 3), but there was no evidence of an association with gains in adulthood. However, adult BMI gains were important after excluding suspected secondary $\mathrm{OA}$ and unilateral knee $\mathrm{OA}$ (see online supplementary figures S4 and S7). In women, BMI increases from childhood to adolescence (7-15 years) and in adulthood were positively associated with knee OA (figure 3).

\section{Life course models of knee $\mathrm{OA}$ risk}

Tests of life course models suggested that there was no additional benefit from including an early BMI measure (15 years) once adult BMI has been accounted for, so we restricted these tests to BMI exposures at 26 and 43 years to increase statistical power. In men, the most parsimonious model with the most support (highest $\mathrm{p}$ value) included a single term for high BMI at 43 years (table 1 ), suggesting that BMI in mid-adulthood was most important in explaining knee OA risk. However, there was still strong support for an accumulation model (duration of exposure). In women, the accumulation (duration and age of exposure) model had the most support, with a high BMI at 43 years having a stronger association with knee OA (OR 2.64 (95\% CI 1.80 to 3.87$)$ ) than a high BMI at 26 years (OR 1.51 (95\% CI 1.02 to 2.24$)$ ).

\section{DISCUSSION}

Our study showed a linear relationship between BMI and midlife knee $\mathrm{OA}$ that was detectable around puberty in female subjects and in early adulthood in male subjects and persisted through life. While these associations appear to have their origins through BMI gains in childhood and adolescence, comparisons of different life course models suggest that the accumulation or duration of exposure in adult life is the main way by which high BMI influences knee OA risk. This implies that having a high BMI in childhood or adolescence is not independently associated with knee OA over and above that acting through BMI in adulthood.

\section{Strengths and limitations}

A key strength of this study is its prospective and longitudinal design, which allowed for a detailed examination of the influence of lifetime BMI on knee $\mathrm{OA}$ and minimised bias from recall, regression dilution and reverse causality, particularly with regards to associations at younger ages where many studies have relied on recall. ${ }^{8-12} 25$ However, with prevalent rather than incident cases, there is the possibility of some reverse causation bias at later ages. While knee OA might lead to reductions in habitual activity and increased BMI, thereby inflating our associations, it is also possible that some individuals with known $\mathrm{OA}$ will reduce their weight to manage their condition, attenuating these associations.

We used the American College of Rheumatology criteria for a symptom-based diagnosis of knee OA. While we did not assess radiographic change and have no data on reliability, there is good evidence to suggest that those with well-defined symptoms also have structural changes on radiographs. ${ }^{26}$ Furthermore, the internal validity of our case classification is supported by the reduced physical performance among cases and by the similar effect sizes we saw compared to other studies that used radiographic criteria. ${ }^{27}$ It thus seems unlikely that our findings would be qualitatively different if radiographic criteria were used. Lastly our results should be generalisable to a similarly aged UK population. ${ }^{28}$

\section{Comparison with other studies and interpretation}

Despite differences in populations, confounders considered and case definition, the effect size and linearity of the association between adult BMI and knee OA were similar to previous

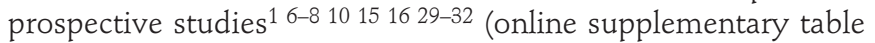
$\mathrm{S} 2$ reports associations in BMI categories). Several studies have reported associations between $\mathrm{BMI}$ at age 20 or 30 years and later knee $\mathrm{OA}^{7-10}$; however, with the exception of one casecontrol study of women, which found a weak association at 
school-leaving age ${ }^{25}$ none has examined BMI at earlier ages. Our findings of associations in childhood for women and in young adulthood for men are thus new.

Conditional BMI gains in periods coinciding with steep adolescent rises in BMI (15-20 years in men and 7-15 years in women) were associated with an elevated risk of knee OA. Although excessive weight during these periods may result in mechanical alteration to the knee joint, ${ }^{7}$ it is also possible that the relationship is a consequence of an underlying metabolic predisposition to both adiposity and $\mathrm{OA}$.

Whichever of these potential mechanisms is at play, our findings support the hypothesis that knee OA risk accumulates from prolonged exposure to high BMI throughout adulthood, with a high BMI in mid-adulthood carrying a slightly greater risk in women. Our sensitivity analysis excluded individuals with a previous knee injury and restricted to cases with bilateral involvement. Associations were generally stronger among this subset, supporting such an accumulation model for this particular disorder. The inclusion of cases of knee OA where BMI is not a component cause ${ }^{28}$ would dilute any attempt to disentangle the role of lifetime BMI among cases where it is a necessary component; this is possibly also reflected in the associations between weight gain and $\mathrm{OA}$ that, while evident in women, were only evident among the bilateral OA cases in men. No other studies have attempted to disentangle how BMI over life is related to knee OA using the methods employed here, ${ }^{24}$ although there is support for an accumulation model from studies that have shown a relationship between early adult BMI and knee OA after adjustment for later weight. ${ }^{73}$

The higher risk conferred by adult BMI in women was explained by the scale and functional form of the BMI exposure in the sense that a $z$-score increase in women represents a larger shift in raw units of BMI than in men, as visible in an earlier study, ${ }^{34}$ and that the distribution of BMI is more skewed in women. It would be interesting to see whether the sex differences reported in studies that used distributional units of $\mathrm{BMI}^{6} \mathrm{~g}^{12}{ }^{15-18}$ would remain when continuous units of kilograms per meter squared are used.

Women had a higher prevalence of knee OA, similar to that reported in population-based cohort studies ${ }^{6}$ and in primary care. ${ }^{35}$ Differences in BMI were unable to explain these genderspecific prevalences; reproductive hormone status presents one possible mechanism.

\section{Implications}

The importance of weight control throughout life as a means of primary prevention of knee OA is emphasised by our finding that BMI is associated with later knee OA as early as 11 years in women and 20 years in men, and by the suggestion that risk from a high BMI accumulates through adulthood. It is further emphasised by the tendency of BMI to track from childhood to adulthood, meaning that weight control interventions that start earlier in life may be more effective. However, our results also suggest that an individual can stop accumulating risk by reducing weight at any stage in adulthood.

Being overweight is a major factor in the aetiology of knee $\mathrm{OA}$ - the increase in knee OA risk per unit increase in BMI is similar to that reported for mortality from vascular disease (Prospective, 2009 479/id). ${ }^{36}$ Our findings extend our understanding of this relationship by highlighting the role of lifetime $\mathrm{BMI}$ in knee OA risk. Rising secular patterns of obesity (particularly in children), ${ }^{37}$ combined with our ageing population, mean that the prevalence of knee $\mathrm{OA}$ is likely to rise in future generations. ${ }^{38}$ Future research into the mechanisms of knee OA in obesity and into the effectiveness of weight control across life in preserving musculoskeletal health are essential to best inform how to tackle these trends.

Acknowledgements The authors thank all the participants of the National Survey of Health and Development and all staff involved in data collection and data entry.

Funding AKW, SB, RC, CC, RH and DK were supported by the UK Medical Research Council. KRM was supported by the Intramural Research Program, National Institute on Aging, National Institute of Health, USA. RJC was supported by the Ministry of Defence, UK. The funders of the study had no role in study design, data collection, data analysis, data interpretation or writing of this manuscript.

Ethics approval This study was conducted with the approval of the Medical Research Council ethics committee.

Provenance and peer review Not commissioned; externally peer reviewed.

\section{REFERENCES}

1. Blagojevic M, Jinks $\mathbf{C}$, Jeffery $A$, et al. Risk factors for onset of osteoarthritis of the knee in older adults: a systematic review and meta-analysis. Osteoarthritis Cartilage 2010;18:24-33

2. Felson DT, Goggins J, Niu J, et al. The effect of body weight on progression of knee osteoarthritis is dependent on alignment. Arthritis Rheum 2004;50:3904-9.

3. Niu J, Zhang YQ, Torner J, et al. Is obesity a risk factor for progressive radiographic knee osteoarthritis? Arthritis Rheum 2009;61:329-35.

4. Sharma L, Song J, Felson DT, et al. The role of knee alignment in disease progression and functional decline in knee osteoarthritis. JAMA 2001;286:188-95.

5. Cooper C, Snow S, McAlindon TE, et al. Risk factors for the incidence and progression of radiographic knee osteoarthritis. Arthritis Rheum 2000;43:995-1000.

6. Felson DT, Zhang Y, Hannan MT, et al. Risk factors for incident radiographic knee osteoarthritis in the elderly: the Framingham Study. Arthritis Rheum 1997:40:728-33.

7. Gelber AC, Hochberg MC, Mead LA, et al. Body mass index in young men and the risk of subsequent knee and hip osteoarthritis. Am J Med 1999;107:542-8.

8. Hart DJ, Doyle DV, Spector TD. Incidence and risk factors for radiographic knee osteoarthritis in middle-aged women: the Chingford Study. Arthritis Rheum 1999;42:17-24.

9. Holmberg $\mathbf{S}$, Thelin A, Thelin N. Knee osteoarthritis and body mass index: a population-based case-control study. Scand J Rheumatol 2005;34:59-64.

10. Lohmander LS, Gerhardsson de Verdier M, Rollof J, et al. Incidence of severe knee and hip osteoarthritis in relation to different measures of body mass: a populationbased prospective cohort study. Ann Rheum Dis 2009;68:490-6.

11. Manninen $\mathbf{P}$, Riihimaki $H$, Heliövaara $M$, et al. Weight changes and the risk of knee osteoarthritis requiring arthroplasty. Ann Rheum Dis 2004;63:1434-7.

12. Holliday KL, McWilliams DF, Maciewicz RA, et al. Lifetime body mass index, other anthropometric measures of obesity and risk of knee or hip osteoarthritis in the GOAL case-control study. Osteoarthritis Cartilage 2011;19:37-43.

13. Aspden RM. Obesity punches above its weight in osteoarthritis. Nat Rev Rheumatol 2011; 7:65-8.

14. Ben-Shlomo Y, Kuh D. A life course approach to chronic disease epidemiology: conceptual models, empirical challenges and interdisciplinary perspectives. Int J Epidemiol 2002;31:285-93.

15. Felson DT, Anderson JJ, Naimark A, et al. Obesity and knee osteoarthritis. The Framingham Study. Ann Intern Med 1988;109:18-24.

16. Manninen P, Riihimäki H, Heliövaara $M$, et al. Overweight, gender and knee osteoarthritis. Int J Obes Relat Metab Disord 1996;20:595-7.

17. Sandmark H, Hogstedt C, Lewold S, et al. Osteoarthrosis of the knee in men and women in association with overweight, smoking, and hormone therapy. Ann Rheum Dis 1999:58:151-5.

18. Tukker A, Visscher TL, Picavet HS. Overweight and health problems of the lower extremities: osteoarthritis, pain and disability. Public Health Nutr 2009;12:359-68.

19. Wadsworth ME, Butterworth SL, Hardy RJ, et al. The life course prospective design: an example of benefits and problems associated with study longevity. Soc Sci Med 2003;57:2193-205.

20. Altman R, Asch E, Bloch D, et al. Development of criteria for the classification and reporting of osteoarthritis. Classification of osteoarthritis of the knee. Diagnostic and Therapeutic Criteria Committee of the American Rheumatism Association. Arthritis Rheum 1986;29:1039-49.

21. Kuh D, Bassey EJ, Butterworth S, et al. Grip strength, postural control, and functional leg power in a representative cohort of British men and women: associations with physical activity, health status, and socioeconomic conditions. J Gerontol A Biol Sci Med Sci 2005;60:224-31.

22. Cole TJ. The LMS method for constructing normalized growth standards. Eur J Clin Nutr 1990:44:45-60.

23. Sharma $\mathbf{L}$, Chang A. Overweight: advancing our understanding of its impact on the knee and the hip. Ann Rheum Dis 2007;66:141-2.

24. Mishra G, Nitsch D, Black S, et al. A structured approach to modelling the effects of binary exposure variables over the life course. Int J Epidemiol 2009;38:528-37. 
25. Dawson J, Juszczak E, Thorogood M, et al. An investigation of risk factors for symptomatic osteoarthritis of the knee in women using a life course approach. J Epidemiol Community Health 2003;57:823-30.

26. Zhang W, Doherty M, Peat G, et al. EULAR evidence-based recommendations for the diagnosis of knee osteoarthritis. Ann Rheum Dis 2010;69:483-9.

27. Felson DT, Zhang Y. An update on the epidemiology of knee and hip osteoarthritis with a view to prevention. Arthritis Rheum 1998;41:1343-55.

28. Felson DT. Identifying different osteoarthritis phenotypes through epidemiology. Osteoarthritis Cartilage 2010;18:601-4.

29. Abbate LM, Stevens J, Schwartz TA, et al. Anthropometric measures, body composition, body fat distribution, and knee osteoarthritis in women. Obesity (Silver Spring) 2006;14:1274-81.

30. Grotle M, Hagen KB, Natvig B, et al. Obesity and osteoarthritis in knee, hip and/ or hand: an epidemiological study in the general population with 10 years follow-up. BMC Musculoskelet Disord 2008;9:132.

31. Järvholm B, Lewold $S$, Malchau $H$, et al. Age, bodyweight, smoking habits and the risk of severe osteoarthritis in the hip and knee in men. Eur J Epidemiol 2005;20:537-42.
32. Reijman M, Pols HA, Bergink AP, et al. Body mass index associated with onset and progression of osteoarthritis of the knee but not of the hip: the Rotterdam Study. Ann Rheum Dis 2007:66:158-62.

33. Hart DJ, Spector TD. The relationship of obesity, fat distribution and osteoarthritis in women in the general population: the Chingford Study. J Rheumatol 1993;20:331-5.

34. Anderson JJ, Felson DT. Factors associated with osteoarthritis of the knee in the first national Health and Nutrition Examination Survey (HANES I). Evidence for an association with overweight, race, and physical demands of work. Am J Epidemiol 1988;128:179-89.

35. Bedson J, Jordan K, Croft P. The prevalence and history of knee osteoarthritis in general practice: a case-control study. Fam Pract 2005;22:103-8.

36. Prospective SC. Body-mass index and cause-specific mortality in 900000 adults: collaborative analyses of 57 prospective studies. Lancet 2009;373:1083-96.

37. Caballero B. The global epidemic of obesity: an overview. Epidemiol Rev 2007:29:1-5

38. Peat G, McCarney R, Croft P. Knee pain and osteoarthritis in older adults: a review of community burden and current use of primary health care. Ann Rheum Dis 2001;60:91-7. 